\title{
A TRAJETÓRIA DE JOSEPH JUBERT PROFESSOR FRANCÊS E ANARQUISTA: A INSTRUÇÃO LIBERTÁRIA SILENCIADA E REPRIMIDA
}

\author{
Sandra Aparecida de Souza ${ }^{1}$ \\ Maria de Fátima Guimarães ${ }^{2}$ \\ Rodrigo Ribeiro de Paiva ${ }^{3}$ \\ Adriel de Moura Cabral ${ }^{4}$
}

\begin{abstract}
Resumo: Esta pesquisa em andamento focaliza a trajetória do professor francês e anarquista Joseph Jubert Rivier ${ }^{5}$, no Brasil, de 1900 à 1920. Com o objetivo de investigar suas ações na área da educação, problematizando a instrução libertária proposta pelos anarquistas. A pesquisa possui registro da presença desse professor nas cidades de Atibaia $(\mathrm{SP})$, Bragança (SP), Sorocaba (SP) e Bauru (SP). Para atingirmos tais objetivos estamos pesquisando diferentes fontes históricas, dentre elas Documentos do Judiciário da Comarca de Bragança Paulista, custodiados pelo CDAPH, da Universidade São Francisco-USF, e periódicos como: A Lanterna (SP), O Operário (SP), no Arquivo Edgard LeuenrothUNICAMP, CDAPH-USF e Biblioteca Nacional. A pesquisa se justifica para a História da Educação por se tratar de um projeto de instrução libertária que se contrapôs ao modelo republicano de educação vigente no início do século XX, além de ser o único sobre J. Jubert Rivier.
\end{abstract}

Palavras-chave: Professor. Anarquista. Instrução Libertária

\section{THE TRAJECTORY OF JOSEPH JUBERT FRENCH TEACHER AND ANARCHIST: THE LIBERTARIAN INSTRUCTION SILTED AND SUPPRESSED}

\begin{abstract}
This ongoing research focuses on the trajectory of French teacher and anarchist Joseph Jubert Rivier, in Brazil, from 1900 to 1920. In order to investigate their actions in the field of education, problematizing the libertarian instruction proposed by the anarchists. The research has a record of the presence of this teacher in the cities of Atibaia (SP), Bragança (SP), Sorocaba (SP) and Bauru (SP). In order to achieve these objectives, we are researching different historical sources, among them judicial documents of the District of Bragança Paulista, custodian by the cdaph, of the Universidade São Francisco-USF, and periodicals such as: The Lantern (SP), the Worker (SP), in the Edgard Leuenroth-UNICAMP, Cdaph-USF and National Library archives. The research is justified for the history of education because it is a project of libertarian instruction that opposed the republican model
\end{abstract}

\footnotetext{
1 Professora e doutoranda em Educação-Universidade São Francisco-USF, sandraa.souza@usf.edu.br

2Professora e doutora em Educação - Universidade São Francisco - USF, fatima.guimarães@usf.edu.br

${ }^{3}$ Mestrando em Educação-Universidade São Francisco-USF, adriel.cabral@usf.edu.br

${ }^{4}$ Mestrando em Educação-Universidade São Francisco-USF, rodrigo.paiva@usf.edu.br

${ }^{5}$ Começa a ser utilizado apenas em Sorocaba, possivelmente para despistar a justiça após sair de Bragança.

Criar Educação, Criciúma, v. 7, no2, jul/nov 2018.- PPGE - UNESC
} 
of education prevailing in the early twentieth century, besides being the only one about $\mathrm{J}$. Jubert Rivier.

Keywords: Teacher. Anarchist. Libertarian instruction

\section{Introdução}

Esta pesquisa em andamento focaliza a trajetória do professor francês e anarquista Joseph Jubert Rivier, no Brasil, no período de 1900 à 1920. Com o objetivo de investigar suas ações na área da educação, problematizando a instrução libertária proposta pelos anarquistas. Trata-se de uma pesquisa histórica, na área da História da Educação do ensino superior no Brasil. Insere-se na linha Educação, Sociedade e Processos Formativos do Programa de Pós-Graduação Stricto Sensu em Educação da Universidade São Francisco (USF) e articula-se ao Grupo de Pesquisas Rastros: História, Memória e Educação, certificado pelo CNPq, sob a liderança dos professores Dra. Maria de Fátima Guimarães e Dr. Elison Paim.

A metodologia abrange a análise documental, sobretudo, de Processos do Fundo do Poder Judiciário da Comarca de Bragança, depositados no CDAPHCentro de Documentação e Apoio a Pesquisa em História da Educação, na Universidade São Francisco-USF, Campus Bragança. Periódicos da época tais como: A Lanterna (SP), O Operário, em Sorocaba (SP), depositados em diferentes arquivos tais como o Arquivo Edgard Leuenroth-UNICAMP, Biblioteca Nacional e Acervo da UNESP. Os referenciais teóricos que sustentam a pesquisa se baseiam em Walter Benjamin $(1987,1989)$ quando discute história, modernidade, sociedade capitalista. Se pauta em Munakata (1980) para discutir a presença do Estado, propriedade e ausência dos direitos trabalhistas nas relação liberal. Ainda recorre a Gallo; Moraes (2005) e Ghiraldelli Jr. (1987) na perspectiva da análise sobre a instrução libertária tema que também compõe o objeto de pesquisa e estudo.

A justificativa da pesquisa se dá por abordar questões ainda pouco discutidas na área da educação, bem como por se tratar de um projeto que se colocou em 


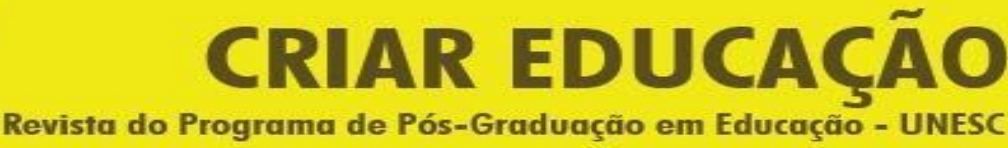 \\ unesc PPG:

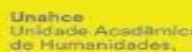 \\ ediunese}

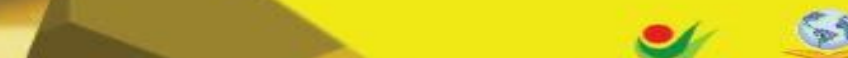

contraste com o modelo de educação republicana em vigor no período, por se direcionar aos filhos de operários e aos próprios operários, além de abordar questões sobre o movimento operário pelo viés de Joseph Jubert Rivier, contribuindo assim com a história da educação. Para expor nossas evidências em primeiro lugar trazemos uma discussão teórica sobre história, memória, trabalho, capitalismo e sensibilidades para compreensão de uma educação libertária e crítica; em segundo lugar trazemos a discussão sobre educação libertária; em terceiro lugar trazemos a discussão sobre o Joseph Jubert Rivier, suas ações e as repressões sofridas por ele; por útimo trazemos as considerações parciais.

\section{Teorias e discussões previlegiando o diálogo com Walter Benjamin}

Para iniciar os relatos de nossa pesquisa promovemos um diálogo com Walter Benjamin, que nos ajuda a analisar e refletir sobre perspectivas da história, da modernidade, do trabalho e da sociedade capitalista para compreender a educação libertária e crítica proposta pelo movimento anarquista, evidenciado através da trajetória do professor anarquista francês Joseph Jubert Rivier, nosso objeto de análise.

Por que privilegiar Walter Benjamin para discutir história? De acordo Lowi (2005) as teses de Benjamin que discutem conceito de história é considerada um dos trabalhos mais relevantes do século $X X$, sobre filosofia e política e estão pautados em três vertentes: romantismo alemão, messianismo judaico e marxismo. Lowi (2005, p. 35) ainda afirma que Benjamin

"[...] é o portador de um significado que supera, de longe, a constelação trágica que o fez nascer. Se, ainda hoje, ele tem a nos dizer, se suscita tanto interesse, discussões, polêmicas, é porque, atravé do prisma de um momento histórico determinado, ele coloca questões relativas a toda a história moderna e ao lugar do século XX, no percurso social da humanidade"

Ou seja, Benjamin embora tenha vivido experiências trágicas em sua vida, seu conhecimento muito contribui conosco até atualidade, pois seus textos são 
profundamente críticos e realistas quanto ao 'progresso modernizante' do início do século XX que ele experenciou, e esse período é exatamente o que nos interessa. Pois, a passagem da sociedade agrária para a sociedade moderna e industrializada é o momento em que surge a resistência, logo o momento em que as ações de Joseph Jubert permeiam por cidades do interior paulista.

Benjamin (1989) ao discutir a modernidade vai minuciosamente mostrando como os aparatos do capitalismo vão se instalando em todas as esferas, como a exemplo da fotografia que "[p]renuncia o seu lugar na história da técnica"(p. 34), ou a mercadoria e o desejo incessante pelo sempre novo, no qual o autor discorre muito bem discorrendo que:

\begin{abstract}
Sua meta: o novo [...] O novo é uma qualidade que independe do valor de uso da mercadoria. È a origem da falsa aparência, que pertence de modo inalienável e intransferível às imagens geradas pelo inconsciente coletivo. É a quintessência da falsa consciência, cujo incansável agente é a moda. Essa falsa aparência de novidade se reflete, como um espelho em outro, na falsa aparência do sempreigual, do eterno retorno do mesmo. O produto desse processo de 'reflexão' é a fantasmagoria da ' história da cultura', em que a burguesia saboreia a sua falsa consciência (idem, p. 40)."
\end{abstract}

O que Benjamin (1989) debate é a relação da alienação pela busca do novo, do novo pelo novo, não pela necessidade ou consciência. O que se tratava de uma questão preocupante, porque qualquer dispositivo de novidade levava o público a se desligar de questões relevantes como a consciência de classe, a resistência, a necessidade da crítica do conhecimento, ou da falta de conhecimento, fato que se tornou um elemento importante para os anarquistas, que se desembocou na organização de escolas Modernas, também chamadas de racionalistas, e ou, libertárias ${ }^{6}$.

Benjamin (1989) ainda comenta das exposições nacionais da indústria que possuiam o objetivo de alegrar o trabalhador, mas o momento foi crucial para o operário se tornar consumidor. Ou, o momento da ilusão do consumo, pois com a precarização do trabalho nas indústrias, operários se viam cada vez mais suprimidos

\footnotetext{
${ }^{6}$ Definições que serão discutidas em segundo lugar.

Criar Educação, Criciúma, v. 7, no2, jul/nov 2018.- PPGE - UNESC
} 
pelas condições insalubres de moradia, atacados pelas doenças e pela falta de garantias no trabalho, haja vista que neste momento não existiam as leis trabalhistas que pudessem respaldar trabalhadores nos momentos de conflito.

Conforme debate Munakata (1981) embora o anarquismo em algumas situações apresentasse características parecidas com o liberalismo econômico tal como: liberais prezam pelos contratos de trabalho sem a intervenção do Estado, e nisso se assemelha ao anarquismo que é contra o Estado, que prega a extinção do Estado, que o considerava repressor por excelência e defendeu a representação direta. Mas opostamente, em nada se equiparou quando se tratou do operário, e esta questão se vê claramente nas relações de trabalho.

O movimento operário era violentamente reprimido pelo Estado, enquanto que o liberalismo econômico se beneficiava da repressão do Estado ao operário, para que a propriedade privada fosse mantida pelo regime de força. Inclusive Jonh Locke um clássico liberal do séc. XVIII previa dura repressão a elementos que viessem a causar interferência na propriedade privada7. Logo, Joseph Jubert Rivier um anarcossindicalista que além de ter defendido a extinção da propriedade privada, era adepto a criação das Ligas Operárias, dos sindicatos de classe, e como os outros anarcossindicalistas era sensível as mazelas que os operários enfrentavam tais como o desemprego, as doenças, a invaliz, desta forma estar associado a algumas entidades da época poderia representar um pouco mais de segurança (MUNAKATA, 1981).

Retomando a perspectiva histórica de Benjamin, encontramos apoio ao narrar a trajetória de Joseph Jubert Rivier considerando as diferentes vozes que permearam o seu meio, pois o autor considera que

O cronista que narra os acontecimentos, sem distinguir entre os grandes e os pequenos, leva em conta a verdade de que nada do que um dia aconteceu pode ser considerado perdido para a história. Sem dúvida, somente a humanidade redimida poderá apropriar-se totalmente do seu passado. Isso quer dizer: somente para a humanidade redimida o passado é citável, em cada um dos seus momentos. Cada momento vivido transforma-se numa citation à

\footnotetext{
7 Um privilégio restrito a capitalistas latifundiários e donos de industrias naquele dado momento. Criar Educação, Criciúma, v. 7, no2, jul/nov 2018.- PPGE - UNESC
} 
l'ordre du jour - e esse dia é justamente o do juízo final (1987, p. 223).

A afirmação do autor nos remete a considerar o perdão e a aceitação, pois quem narra precisa não apenas da compreensão do passado, mas também do cuidado em revelar a veracidade dos fatos nos seus mais diferentes momentos.

Benjamin (1987, p. 223) ainda debate que "[a] luta de classes, que um historiador educado por Marx jamais perde de vista, é uma luta pelas coisas brutas e materiais, sem as quais não existem as refinadas e espirituais. Ou seja, pedir para a classe de trabalhadores miseráveis e excluídos que estivessem afeitos a evolução humanística, sem ter acesso aos bens básicos de consumo era esperar inutilmente, a humanização é consequência de conquistas materiais, intelectuais e de valorização das mesmas.

Joseph Jubert Rivier embora seguisse o movimento anarquista, também considerava a luta de classes, acreditava que os trabalhadores só seriam livres a partir da abolição das classes sociais e que o capital deveria estar a serviço do trabalhador. No entanto, não descartava como um meio para libertação do opressão: o melhoramento técnico, higiênico, intelectual e moral da classe.

Ainda nos apoiando em Benjamin (1987), concordamos que um dos aparatos tecnológicos mais importantes da burguesia, que caracterizou no auge do capitalismo foi a mídia. Quando a informação exerceu fortemente o seu papel na modernidade. Embora o autor atribuia a informação ao declínio da narrativa, adiante nos valeremos dela para discutir a presença de Joseph Juber Rivier na imprensa.

$\mathrm{Na}$ segunda parte do texto iremos discutir o contexto da instrução libertária, as ações e a presença de Joseph Jubert Rivier nas escolas modernas.

\section{O contexto da instrução libertária e a presença de Joseph Jubert Rivier}

Neste momento traremos a discussão da instrução libertária a partir de referenciais teóricos tais como Ferrer y Guardia (2010), Fregoni (2007), Gallo e Moraes (2005), Rodrigues (1988) e Ghiraldelli Jr. (1987), a presença de Joseph Jubert Rivier nas escolas modernas e suas ações como professor. 
Mas o que é a instrução libertária? Bem, os anarquistas defendiam que para organizar uma sociedade sem classes, sem a presença do Estado era necessário uma instrução que libertasse o ser humano da opressão do trabalho, promovida pelas elites. Contudo, falamos do final do século XIX e início do século XX o que significa que, o cientificismo estava em alta, o Estado tinha se consolidado como laico e os anarquistas rejeitavam a instrução religiosa, logo a denominaram como instrução racionalista, pautada pela razão, pela ciência e não mais pela fé.

O pedagogo espanhol Francisco Ferrer y Guardia $^{8}$ fundador da primeira Escola Moderna de Barcelona em 1901, propôs que a instrução libertária tinha como objetivo "[...] fazer com que os meninos e as meninas que lhe [eram] confiados se [tornassem] pessoas instruídas, verdadeiras, justas e livres de qualquer preconceito" (FERRER Y GUARDIA, 2010, p. 7). Ou seja, o estudo religioso estaria sendo substituido pelo libertário, racional com base nas ciências naturais e não mais pelo religioso.

Joseph Jubert Rivier que disseminava a ideologia libertária proposta por Ferrer y Guardia e atuou como professor em duas escolas modernas, uma delas em Sorocaba e outra em Bauru, afirmou que [...] a execução de Ferrer pelo jesuitismo hespanhol lança um raio de indignação entre aos homens que se deixam guiar pela razão e [que a] mocidade sã, as mais carinhosas começam a compreender que todas as religiões do mundo não perfazem uma boa [...] educação de seus filhos [...]. Joseph Jubert (A LANTERNA, 31/12/1910, n. 64, p. 2). Ou seja, a execução gerou ainda mais críticas a educação religiosa.

Para Gallo e Moraes (2005) que discute a ação de Paul Robin ao fazer de um orfanato uma escola libertária. Afirma que o ser humano necessitava de uma educação completa, capaz de construir a liberdade, esta educação englobava o desenvolvimento do intelecto, do físico e da moral. Dentre o desenvolvimento do físico estava a educação voltada para o esporte e para os jogos, a educação manual que previa aperfeiçoar o centro motor de crianças menores, e por fim e mais relevante a educação para a profissão, que incluia oficinas de treinamento para trabalhos com madeira, metais, papéis, tecidos, plantação e limpeza.

\footnotetext{
${ }^{8}$ Fuzilado em 1909 pelo Estado por apresentar ideias que subvertiam a ordem da época.
}

Criar Educação, Criciúma, v. 7, no2, jul/nov 2018.- PPGE - UNESC 
De acordo com Fregoni (2007, p. 15) que se apoiou em Tiana (1987) a instrução libertária "significava a ausência de dogmas, o livre discurso da razão, a confiança do homem em si mesmo sem recorrer a interpretações mágicas sobre a existência. Seu objetivo central seria a construção de uma verdadeira personalidade humana tendo a liberdade como requisito indispensável". Ou seja, a autora se pauta em dois elementos básicos que é a razão e a liberdade.

Fregoni (2007, p. 99) ao reproduzir o que Jomini (1990) afirmou, mostra que Joseph Jubert esteve na função de professor conforme se observa:

as instituições escolares libertárias estavam a cargo de militantes ou simpatizantes do movimento. Para comprovar sua afirmação, faz uma lista com os nomes de vários professores de escolas racionalistas, bem como a instituição em que atuaram como professores. Assim, aparecem os nomes dos anarquistas Adelino de Pinho, Pedro Matera, Edmundo Rossoni, João Penteado, José Alves, Élvio Nervi, Joseph Joubert e Florentino de Carvalho.

Vários outros autores e autoras tais como Ferreira e Boschette (2016), Valente (2014), Gonzaga (2010), Peres (2004), D’Angelo (2000), Ghiraldelli Jr. (1987) citaram Joseph Jubert Rivier como professor da Escola Moderna de Sorocaba ou Bauru, mas em nenhum texto deles ou delas encontramos referências sobre a sua formação. Uma questão importante é que Ghiraldelli Jr. (1987) se refere a ele como professor e marceneiro; Ferreira e Boschette (2016) mencionam que além de professor ele foi administrador da escola moderna de Sorocaba nos anos de 1911-1912. Valente se apoiou nas informações de Cavalheiro (2009).

Segundo Ghiraldelli Jr. (1987) a luta pela instrução era séria, não objetivava ludibriar os trabalhores, pois em nenhum momento a instrução se descolava da ação social, que os próprios operários foram capazes de compreender, que a instrução antes daquele momento foi sempre apropriada pela elite. Inclusive que os libertários estavam sempre de olho para que a educação não se desenvolvesse sozinha e corresse o risco de se desunir dos objetivos que era: a transformação da sociedade, pois os trabalhadores possuiam esse compromisso com o meio operário.

Conforme Rodrigues (1988, p. 165) A escola moderna n. 2 "[...] servi[u-se] do método indutivo demonstrativo e objetivo e base[ou]se na experimentação, nas 
afirmações científicas e raciocinadas, para que os alunos [tivessem] uma idéia clara do que se Ihes quer[ria] ensinar". Se previa a educação artística, intelectual e moral.

Ainda para Rodrigues (1988, p. 166) para fins da intrução o que se previa era um "ser humano educado, instruído, culto, despido de ódio, de rancor, de inveja, de ambições, amigo da razão e da verdade, com capacidade para se autogovernar, gerir seus atos, ser livre e cultivar a liberdade como a vida, todos os dias, e dentro da coletividade $[\ldots]$.

Uma questão se faz necessária neste momento: A instrução libertária incomodava a elite por se contrapor a educação religiosa e republicana? Analisando as definições sobre a instrução libertária se previu o encontro dessas ideias as de Joseph Jubert Rivier, que através da imprensa pode promover a divulgação conforme se verifica: "[...] mais alto protesto humano contra a tyrannia burguesa e policial, [que] o mundo operário e consciente se une num só pensamento [...]" ( $O$ OPERÁRIO, 01/05/1912, №. 130, p. 440).

Ou ainda, quando em ocasião da comemoração do dia $1^{\circ}$ de maio, a União Operária de Sorocaba promove uma festa que inclui discursos de alunos da Escola Moderna: a exemplo desses: Francisca Cepalho defende a Mulher Operária, Antonio Place defende A Sciencia, a menina Dolores a Liberdade. O fechamento do discurso "[foi feito pelo] exímio professor da União Snr. Joseph [Jubert] Revier ${ }^{9}$ [...]" (O OPERÁRIO, 01/05/1912, ํo. 130, p. 445).

No evento baile dos sócios e sócias da União Operária e convidados (18 de maio de 1912). Alunos de Joseph Jubert Rivier discursaram temas como: a revolução social do México, a emancipação da mulher, valores da Escola Moderna, e anarchia filosófica (O OPERÁRIO, 26/05/1912, n. 134, p.453).

Em Bragança (SP) em 1910, Joseph Jubert Rivier manteve o objetivo de organizar uma escola moderna para operários e seus filhos que não se concretizou, porém em 1911 na cidade de Sorocaba (SP) identificamos que ele esteve a frente de uma escola moderna atuando como professor. E em 1914, o localizamos em Bauru como professor de outra escola moderna, se registra de que ele tenha permanecido lá ao menos até 1916.

\footnotetext{
${ }^{9}$ As notas assinadas por Jubert constam Rivier e não Revier como aqui.

Criar Educação, Criciúma, v. 7, n2, jul/nov 2018.- PPGE - UNESC
} 
A nota a seguir mostra a atuação de Joseph Jubert Rivier, na Escola Moderna de Bauru conforme se lê: "Sociedade Luz - [...] Afim de angariar fundos para a manutenção da <<Escola Moderna>> que mantêm e que agora está a cargo do companheiro Joseph Jubert, foi organizada uma festa que se realizará hoje e amanhã" (A LANTERNA, 02/08/1914, n. 254, p. 3).

A instrução libertária durante o momento pesquisado se mostrou próspera, mas as lideranças anarquistas sofriam muita repressão, o que possivelmente impactava nas Escolas Modernas. Joseph Jubert Rivier foi bastante citado durante os momentos em que esteve a frente das escolas. Vários dos seus artigos foram identificados, enquanto colaborador dos jornais tanto $A$ Lanterna (SP), quanto $O$ Operário (Sorocaba, SP).

Sendo assim, a instrução libertária por se contrapor a educação religiosa e republicana, sofreu diferentes ataques através do seu representante, que escrevia artigos críticos ao padre Leonardo Gioieli responsável pela paróquia de Bragança, que inclusive chegou a ser transferido para outra cidade após o escândalo. Notas publicadas demonstram críticas a Joseph Jubert Rivier e serão discutidas na parte a seguir.

Na terceira parte abordaremos questões sobre Joseph Jubert Rivier relativos a organização da Liga, do movimento operário e dos processos que sofreu.

\section{Joseph Jubert Rivier por entre ações e repressões}

Neste momento do texto trataremos de questões relativas as ações junto ao movimento operário, bem como as repressões sofridas por Joseph Jubert Rivier. Os processos em que constam essas repressões pertencentem ao Fundo do Poder Judiciário da Comarca de Bragança que se encontra depositado no CDAPH-Centro de Documentação e Apoio a Pesquisa em História da Educação, nas depedências da Universidade São Francisco-USF em Bragança Paulista, SP.

Joseph Jubert Rivier ao chegar em Bragança organiza uma Liga Operária em Assembleia no dia 9 de setembro de 1910, elabora um Estatutos da Liga, confecciona e distribui boletins nas versões português e italiano denunciando sobre as precárias condições de vida dos colonos, nas fazendas de café da região. Criar Educação, Criciúma, v. 7, no2, jul/nov 2018.- PPGE - UNESC 
Estimamos que ele tenha chego em Bragança por volta de 1908, pois ao menos é o que fica claro na sua afirmação, durante o julgamento; ser morador de Bragança há mais ou menos três anos.

Por conta da distribuição dos boletins um grupo de fazendeiros da região de Bragança se unem para fazer uma queixa ao delegado Azevedo Marques. Nesse momento então, é aberto um inquérito para se investigar o caso. Ele é processado, porém neste processo não é condenado. Contudo Joseph Jubert Rivier também escreve críticas ao padre Leonardo Gioiele, conforme mencionando anteriormente e que será retomado mais adiante.

Em Bragança, Joseph Jubert Rivier mobilizou colonos para resistirem à exploração por meio de greves. No próprio Processo Crime (1911) se registra uma mobilização de trabalhadores na Fazenda Boa Vista. Durante o processo ele se defende sem contar com a presença de um advogado, alegando não ser possível confiar em uma justiça que não era neutra, pois ligava juiz, acusador e testemunha, ou seja, todos contra ele, através de laços consanguíneos.

Joseph Jubert ao elaborar o Estatutos da Liga Operária manteve o objetivo de organizar uma escola para operários e seus filhos em Bragança, no entanto após a acusação da distribuição dos boletins, as relações na cidade ficaram tensas. Devido aos artigos no jornal $A$ Lanterna de São Paulo que escrevia sobre o padre Leonardo Gioieli foi processado e teve dificuldade de recorrer.

Diante de tal fato, Joseph Jubert Rivier foi jurado de morte por um membro da família Leme, foi intimado e ameaçado pelo delegado da cidade Azevedo Marques, que disse a ele, caso continue a escrever sobre o padre, ele (delegado) "[...] saltaria os limites da lei e empregaria todas as violências, até ao extremo que fosse necessário, para faze[lo] calar. [...]" (A LANTERNA, 28/1/1911, n. 68, p. 1). Possivelmente diante de tais fatos e dificuldades alegadas, Joseph Jubert Rivier saiu da cidade rumo a Sorocaba.

Na cidade de Sorocaba (SP) localizamos Joseph Jubert Rivier atuando como professor numa Escola Moderna, no final do ano de 1911. Na cidade ele continuou a denunciar os abusos praticados por parte de pessoas ligadas a industrialização e ao capitalismo que vinha se mostrando cada vez mais presente. Em 1912, relatou a 
exploração de funcionários de industrias na cidade de Votorantim (SP), até que em 1913, ele sofreu um novo processo e perseguição, chegando a ser preso durante 4 meses e condenado a pagar uma multa. Após sair da prisão e relatar tudo o que passou dentro dela, exatamente um ano depois o identificamos como professor de outra Escola Moderna, mas desta vez em Bauru (SP).

Ainda que possamos confirmar pelas notícias, que Joseph Jubert Rivier atuou como professor nas duas escolas modernas mencionadas, que escreveu diversos artigos no jornal $A$ Lanterna, que atuou como advogado em sua própria defesa em Bragança, não temos confirmação da sua formação, como professor. Identificamos que ele mesmo se declarou professor nos três momentos diferentes do processo em Bragança. Além de todo o engajamento político durante a organização da Liga Operária, elaboração do Estatutos da Liga Operária, ele também se mostrou um anarcossindicalista ativo que seguiu em busca dos objetivos, pois transitava nos locais conflitantes.

Aliás, esse trânsito de Jubert flagrado em suas próprias palavras conforme se lê: "[...em] todos paises que percorri, Europeus e Americanos, desde as mais populosas cidades aos mais afastados sertões, não encontrei um operário análogo ao de Sorocaba. [...]" (O OPERÁRIO, 02/06/1912, n. 135, p. 455), nos alerta para a forte organização que existia entre os anarquistas, tais como forma de comunicação, atos de mobilização, organização de escolas, elaboração de conferências, teatros, sem contar as parcerias que promoveram com outros membros de fora da militância.

Por fim, ameaças sofridas por Joseph Jubert Rivier sucitavam o interesse da mídia, jornais opositores divugaram sua prisão, se referindo a ele de forma pejorativa. No entanto contrariamente uma grande campanha contra sua prisão foi feita por diferentes jornais, inclusive o caso dele tomou proporções nacionais ao ser anunciado pelo jornal A Voz do Operário no Rio de Janeiro. Na sequência traremos as considerações finais. 


\section{Considerações finais}

A pesquisa buscava investigar as ações na área da educação, problematizando a instrução libertária vista através da trajetória de Joseph Jubert Rivier, bem como levantou duas questões, uma delas: O que é instrução libertária? E a outra: Se a instrução libertária se contrapôs a educação religiosa e republicana? Desta forma chegamos ao resultado de que o conceito visava a libertação da opressão do trabalho, a reestruturação de uma sociedade sem classes, os ideais de melhoramento intelectual, moral e higiênico, a busca pela liberdade, bem como um ensino racional que afastasse a fé (elemento considerado principal até o dado momento). As ações foram fortemente reprimida e silenciada, sobretudo as manifestações, conferências e greves.

\section{Fontes}

Processo Crime - Fundo do Poder Judiciário da Comarca de Bragança, depositado no CDAPH-USF
A Lanterna - Arquivo digital Biblioteca Nacional
O Operário - Edição Facsimilar, Sorocaba

\section{Referências}

BENJAMIN, W. Magia e técnica, arte e política - Obras escolhidas. Ensaios sobre literatura e história da cultura. Tradução de Sérgio Paulo Rouanet - Vol. 1, São Paulo: Brasiliense, 1987.

BENJAMIN, W. Paris: Paris do segundo Império - Paris capital do século XIX. São Paulo: Brasiliense, 1989.

BOSCHETTI, V. R.; FERREIRA, V. B. A cidade, os movimentos sociais operários e a educação. Quaestio, Sorocaba, SP, v. 18, n. 3, p. 669-687, nov. 2016.

D’ANGELO, Márcia. Caminhos para o advento da escola de aprendizes artífices de São Paulo (1910-1930): Um projeto das elites para uma sociedade assalariada. 2000. f 350. Dissertação (Mestrado em História Econômica). Universidade de São Paulo, São Paulo, 2000.

FERRER Y GUARDIA, Francesc. A escola moderna. Trad. Ateneu Diego Giménez. Piracicaba: Ateneu, 2010. Disponível em: 


\section{CRIAR EDUCAÇ̃̃o}

<https://we.riseup.net/assets/160969/Ferrer\%20e\%20Guardia\%20a\%20escola\%20m oderna.pdf>. Acesso em: $1^{\circ}$ jun. 2015.

FREGONI, O. R. Educação e resistência anarquista em São Paulo: a sobrevivência das práticas da educação libertária na Academia de Comércio Saldanha Marinho (1920 - 1945). 2007. Dissertação de Mestrado - PONTIFÍCIA UNIVERSIDADE CATÓLICA DE SÃO PAULO - PUC - SP, 2007.

GALLO, S.; MORAES, J. D. Anarquismo e educação: a educação libertária na primeira república. In. Histórias e Memórias da Educação no Brasil. STHEFANOU. M.; BASTOS, M. H. C. v. III, Petrópolis, RJ: Vozes, 2005.

GHIRALDELLI JR., P. Educação e movimento operário. São Paulo: Cortez, 1987.

GONZAGA, L. O. Educação libertária e escola pública: Desafios e possibilidades. 2010. Universidade Federal do Rio Grande do Sul, Licenciatura em Letras. Porto Alegre, 2010.

LOWI, M. Walter Benjamin: aviso de incêndio: uma leitura das teses "Sobre o conceito de história"/ Michel Lowi; tradução de Wanda Nogueira Caldeira Brant, [tradução das teses] Jeanne Marie Gagnebin, Marcos Lutz Muller. - São Paulo: Boitempo, 2005 160p. : il.

MUNAKATA, K. A legislação trabalhista no Brasil. São Paulo: Brasiliense, 1981.

PERES, F. A. Estratégias de aproximação: um outro olhar sobre a educação anarquista em São Paulo na Primeira República. 2004. f Dissertação (Mestrado em Educação). Universidade de São Paulo-USP, 2004.

RODRIGUES, E. Os libertários: ideias e experiências anárquicas. Petrópolis, RJ: Vozes, 1988.

VALENTE, M. P. Imprensa e educação: registro da escrita feminina no jornal o operario (1909-1913). 2014. Dissertação de Mestrado. Universidade de Sorocaba, SP, 2014. 